\title{
Nano artroskopi
}

\section{Nano arthroscopy}

\author{
Yusuf Erdem ${ }^{1}$, Çağrı Neyişci
}

${ }^{1}$ Sağlık Bilimleri Üniversitesi Gülhane Tıp Fakültesi, Ortopedi ve Travmatoloji Ana Bilim Dalı, Ankara

${ }^{2}$ Gülhane Eğitim ve Araştırma Hastanesi, Ortopedi ve Travmatoloji Kliniği, Ankara

\begin{abstract}
Artroskopi, tanısal ve girişimsel ortopedik cerrahi işlemlerde sıklıkla kullanılmaktadır. Yaklaşık yüzyılık geçmişe sahip olan artroskopi teknolojisinin gelişmesiyle diz ve omuz eklemi gibi büyük eklemlerin yanı sıra el bileği ve karpometakarpal eklemler gibi küçük eklemlerde de kullanılmaya başlanmıştır. Lokal anestezinin yaygın kullanımıyla ofis artroskopisinin yaygınlık kazanmaya başlaması, artroskopik aletlerin boyutlarının küçülmesi ve elektronik teknolojisindeki yenilikler, nano artroskopiyi hayatımıza sokmuştur. Nano artroskopi artık günümüzde tanısal ve girişimsel artroskopide kullanılmaya başlanmıştır. İndirekt görüntüleme yöntemlerine göre daha az maliyetli olması ve eklem patolojilerinin direkt görülebilmesi nano artroskopinin en büyük avantajlarıdır.
\end{abstract}

Anahtar sözcükler: nano artroskopi; mini artroskopi; iğne artroskopi
Arthroscopy is widely used for diagnostic and interventional orthopedic surgery. Arthroscopy has almost a hundred years old and with the technological development it is used at small joints like wrist and carpometacarpals besides the large joints like knee and shoulder. Commonly usage of local anesthetics bring office arthroscopy; innovation of electronic technology and smaller size arthroscopic instruments bring nano arthroscopy to our lives. Nano arthroscopy is being used at diagnostic and interventional arthroscopy at the present time. Its cost-effectiveness and direct visualization of lesions are the advantages than indirect imaging methods.

Key words: nano arthroscopy; mini arthroscopy; needle arthroscopy

dir. Bu durum daha az hastalık ve ölüm oranıyla hastaların iyileşme süresini hızlandırmaktadır. ${ }^{[1-3]}$

Direkt grafi, bilgisayarlı tomografi ve manyetik rezonans görüntüleme (MRG) gibi indirekt görüntüleme yöntemlerinin teşhis koymada yetersiz kalması, tanısal artroskopi kavramını doğurmuştur. ${ }^{[1-3]}$ Ancak ameliyat hazırlığı, hastane ücretleri ve anestezi altında işlemlerin yapılması da tanısal artroskopide ortopedik cerrahları sınırlayan etkenler olmuştur. Artroskopik cihazların küçük eklemlere uyumlu olarak küçülmesi ile büyük eklemlerde tanısal artroskopinin daha az yumuşak doku hasarı ile yapılmasını ve lokal anestezinin kullanım sıklığının artması ile de artroskopinin günübirlik ofis işlemleri arasında olmasını sağlamıştır. ${ }^{[1-3]}$

Yaklaşık yüzyıllık geçmişe sahip olan artroskopi teknolojisi; diz, omuz, kalça, ayak bileği eklemleri gibi büyük eklemlerin yanı sıra karpometakarpal eklemler gibi küçük eklemlerde de kullanılmaya başlanmıştır. Lokal anestezinin yaygın kullanımı ile ofis artroskopi-

İletişim / Contact: Doç. Dr. Yusuf Erdem •E-posta / E-mail: dryusufoguzerdem@gmail.com

ORCID iD: Yusuf Erdem, 0000-0002-8685-2356 • Çağrı Neyişci, 0000-0001-8481-7808

Geliş / Received: 30 Ekim 2021 • Kabul / Accepted: 16 Aralık 2021 
sinin yaygınlık kazanmaya başlaması, artroskopi aletlerinin boyutlarının küçülmesi ve ortopedik el aletleri teknolojisindeki yenilikler nano artroskopiyi hayatımıza sokmuştur. Nano artroskopi, klasik artroskopinin yerine günümüzde tanısal ve girişimsel işlemlerde kullanılmaya başlanmıştır. İndirekt görüntüleme yöntemlerine göre daha az maliyetli olması ve eklem patolojilerinin direkt görülebilmesi nano artroskopinin en büyük avantajlarıdır. ${ }^{[1-3]}$

\section{TARIHÇE}

İğne artroskopi, mini artroskopi veya nano artroskopi, artroskopik görüntüleme araçlarının belirli bir alt kümesini tanımlamak için kullanılan terimlerdir. Aslında nano artroskopi kavramı 25 yılı aşkın bir süredir bulunmaktadır. Teknolojik gelişmeler ile küçük boyutlarda tek kullanımlık kameraların üretimi nano artroskopi kavramını hayatımıza sokmuştur. Ostendorf ve ark. bir kadavra çalışmasında romatoid artrit teşhisine yardımcı olmak için 1-1,9 mm'lik artroskoplarla nano artroskopi uygulamışlar ve bu durumun sinovyal değişiklikler, kondromalazi ve kemik değişikliklerinin derecelendirilmesine izin verdiğini savunmaktadırlar. Ayrıca metakarpofalangeal eklemlerden hastalığın evrelenmesine yardımcı olmak için sinovyal biyopsiler de yaptıklarını bildirmektedirler. iki portallı teknik kullanarak, eklem yüzeyinin yaklaşık $\% 80$ 'ini görüntüleyebildiklerini ve böylece hastalık hakkında çok önemli bilgiler edindiklerini kaydetmişlerdir. [2] Benzer bir çalışmada, romatoid artritli hasta grubunda nano artroskopi ile tanısal işlemin romatoid artrit ile ilişkili manyetik rezonans görüntüleme (MRG) bulgularıyla mükemmel korelasyon gösterdiği belirtilmektedir. ${ }^{[3]}$

1995 yılında Gramas ve ark.'nın kronik diz ağrısında nano artroskopinin, klasik artroskopinin, fizik muayenenin ve manyetik rezonans görüntülemenin etkinliğini değerlendirmek için dokuz yetişkinde yaptıkları çalışmada, anti-inflamatuar kullanımı ve fizik tedavi gibi rutin konservatif tedavi yöntemlerin başarısız olduğunu, artroskopik girişimle tedavinin üstün olduğunu, nano artroskopinin klasik artroskopiye göre daha az müdahaleci ve menisküs anormalliklerini tespit etmede üstün olduğunu belirtmektedirler. ${ }^{[4]}$

Özellikle 2017'den sonra nano artroskopi ile ilgili çalışmalarda büyük bir artış dikkat çekmektedir. Bu durumun muhtemel sebebi, sağlık hizmetlerinin ve manyetik rezonans görüntülemenin yüksek maliyeti olarak gösterilmektedir. Bununla birlikte eklem içi patolojinin hem tanı hem de tedavisi için ofis içi artroskopinin kolaylığının ön plana çıkarııması amaçlanmaktadır. ${ }^{[4,5]}$

Birçok çalışma, manyetik rezonans görüntüleme ile nano artroskopinin ve klasik artroskopinin etkinliğini değerlendirmektedir. ${ }^{[5-8]}$ Bu çalışmalar, klasik veya nano artroskopi ile yapılan tanısal artroskopinin manyetik rezonans görüntülemeye göre maliyet tasarrufu sağlayabileceği görüşündedir. Gill ve ark. tarafından gerçekleştirilen prospektif, çok merkezli çalışmada tanısal artroskopinin doğruluğu ve güvenirliği manyetik rezonans görüntüleme ile karşılaştırılmaktadır. ${ }^{[9]}$ Çalışmaya, manyetik rezonans görüntüleme çekilen ve sonrasında nano artroskop ve ardından standart bir artroskop kullanılarak tanısal artroskopi yapılan 110 hasta dahil edilmiştir. Elde ettikleri sonuçlar, ofis içi tanısal artroskopinin istatistiksel olarak standart tanısal artroskopiye eşdeğer olduğu şeklindedir. Ofis içi tanısal görüntülemenin dizdeki eklem içi patolojilerde daha doğru bir görüntüleme ve değerlendirme sağladığını belirtmişlerdir. ${ }^{[9,10]}$

Maliyeti ve tanısal doğruluğu daha da iyileştirmek amacıyla, ofis içi nano artroskopi ile birçok çalışma yapılmıştır. Zhang ve ark., tanısal ofis içi nano artroskopi endikasyonlarının sistematik incelemesini sunmuşlardır. ${ }^{[11]}$ Bu derleme dokuz klinik çalışmayı ve iki maliyet analizini içermektedir. Dokuz klinik çalışmanın sonuçları, duyarlılık, özgüllük, pozitif tahmini değer ve negatif tahmini değer açısından MRG'ye kıyasla ofis içi nano artroskopi ile daha üstün sonuçlar alındığını göstermiştir. Maliyet analizi çalışmaları ise, ofis içi nano artroskopinin tanı amaçlı MRG yerine kullanıldığında daha düşük maliyet sağladığını ortaya çıkarmıştır. ${ }^{[10.11]}$ Ofis içi nano artroskopinin, şüpheli bir tanıyı doğrulamakla birlikte tedavi etme sürecini de hızlandırabildiği savunulmaktadır. ${ }^{[10.11]}$

Ofis içi cerrahi prosedür kavramı, güvenlik açısından birçok cerrah için göz korkutucu olabilmektedir. Bir vaka serisinde, 13 bağımsız kurumda tanısal nano artroskopiler değerlendirilmiş ve analize dahil edilen 1419 vakada hiçbir majör komplikasyon (enfeksiyon, kondral toksisite, acil bakım ihtiyacı veya işlemden sonra acil serviste tedavi gibi) yazarlar tarafından bildirilmemiştir. Sadece vakaların \%1,9'unda vazovagal olaylar ve vakaların \%0,3'ünde işlem sonrası ağrı rapor edilmiştir. Ayrıca yazarlar ekleme girmeden önce veya işlemden sonra antibiyotik kullanmadıklarını özellikle belirtmişlerdir. ${ }^{[12]}$

\section{ENDIKASYON}

Nano artroskopi için sürekli genişleyen bir endikasyon listesi bulunmaktadır. Başlangıçta elin küçük eklemleri için bir teşhis aracı olarak tanıtılan bu enstrümanın rolü şimdi diz ve omuza doğru genişlemiştir. Nano artroskopi kesin tanı amaçlı kullanılabildiği gibi eklem içi patolojilerin tedavisinde de nano artroskopik enstrümantasyon yaygınlığını gün geçtikçe arttırmaktadır. Hatta tendoskopi kullanılmaya başlanmıştır. ${ }^{[13]}$ Lavender ve ark. sadece nano artroskopi ve nano enstrümentasyon kullanarak 
basit menisküs yırtıkları için kesisiz parsiyel menisektomi yapabildiklerini bildirmişlerdir. ${ }^{[14]}$

Endikasyonlarının içinde serbest cisim çıkarma, sinovyal biyopsi, glenoid labrum onarımı ve rotator manşet onarımı da bulunmaktadır. ${ }^{[15,16]}$ Nano artroskopi ayrıca, bir eklemin birden fazla kompartmanının aynı anda görüntülenmesine yardımcı olmak için ek bir girişim olarak da kullanılabilir ve ameliyathanede potansiyel olarak zaman tasarrufu sağlamaktadır. Bu aynı zamanda hastayı bir cerrahi kesiden kurtarabilir ve bu sayede olası bir enfeksiyon bölgesini neredeyse ortadan kaldırabilmektedir. ${ }^{[15.16]}$

\section{ENSTRÜMANTASYON}

Birçok şirket, nano artroskopları ve artroskopik enstrümanları piyasaya sürmüştür. Standart bir artroskop, bir kameraya bağlanan bir fiber optik kablo ile yaklaşık 2,7-4,0 mm (kamera kılıfı ise 4-5,9 mm) çapındayken, nano artroskop ise $1,9 \mathrm{~mm}$ çapında (kamera kılıfı ise 2,2 $\mathrm{mm}$ ) çok daha küçük bir dürbündür ve iğnenin ucunda görüntüleme ekranına video ileten bir mikroçip içermektedir. Bu durum; daha küçük kesileri, daha az morbiditeyi ve daha hızlı iyileşme sürelerini ortaya çıkarmıştır. Nano artroskopinin daha minimal müdahaleci olması tanısal ofis artroskopinin başlamasını sağlamıştır. Bu sayede lokal anestezi altında yaklaşık 18-G bir iğne kalınlığında kamera yardımıyla eklem içi görüntülenebilmekte, hasta ile hastalığı ve tedavi yöntemleri ek bir tanısal işleme gerek duyulmadan tartışılabilmektedir. Ayrıca el aletlerinin teknolojik gelişimine bağlı olarak parsiyel menisektomi, Osgood-Schlatter eksizyonu, omuz anterior labrum tamiri ve ayak bileğinden yabancı cisim çıkarılması gibi işlemler de lokal anestezi altında nano artroskopi yar- dımı ile yapılabilir hale gelmiştir. Maliyet analizi, iğne artroskopisinin tanısal amaçlar için manyetik rezonans görüntülemeye göre neredeyse eşdeğer tanısal doğruluk ile daha uygun maliyetli olduğunu göstermiştir. Bu, nano artroskopinin yaygınlaşmasında artışa yol açmıştır. [15.16]

Örnek olarak, en sık kullanılanlardan biri Arthrex (Naples, FL) NanoScope ${ }^{\mathrm{TM}}$ operatif artroskopi sistemidir. Bu sistem, esnek 1,9 mm'lik tek kullanımlık kameranın yanı sıra 2 mm'lik rezeksiyon aletlerini ve kanülleri kullanır. Bu el aletleri içinde problar, makaslar, kavrayıcılar, koparıcılar ve tıraş makineleri dahil olmak üzere neredeyse eksiksiz bir seçenek yelpazesi bulunmaktadır. ${ }^{[3,17]}$ (Şekil 1) (Tablo 1).

Tablo 1. Nano artroskopi teknolojisinin boyutsal küçülme oranları

\begin{tabular}{lc}
\hline & Çap \\
\hline Standart artroskop & $4 \mathrm{~mm}$ \\
Nanoartroskop & $1,9 \mathrm{~mm}$ \\
Küçülme oranı & $\% 53$ \\
& Çap \\
Standart kanül & $5,9 \mathrm{~mm}$ \\
Nano kanül & $2,2 \mathrm{~mm}$ \\
Küçülme oranı & $\% 63$ \\
& Çap \\
Nano el aletleri & $2 \mathrm{~mm}$
\end{tabular}

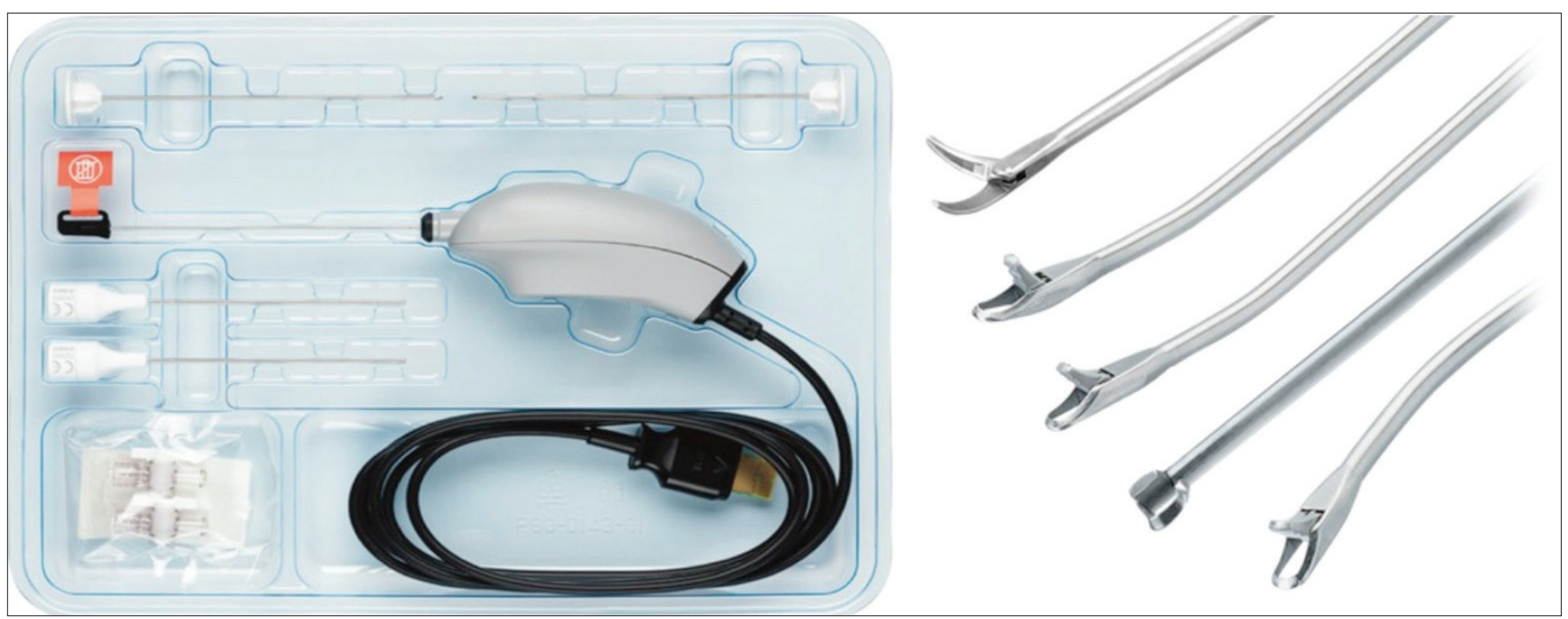

Şekil 1. Tek kullanımlık nanoskop, kamera kiti ve nano el aletleri (Arthrex Naples, FL) (NanoScope ${ }^{\mathrm{TM}}$ ) (Arthrex'in izniyle). 
Üreticiler tarafından farklı nano artroskopi kule kurulumları mümkündür. Ameliyathanede kullanılıyorsa kamera ve kılıf, rutin artroskopide kullanıldığı gibi standart bir artroskopik video monitörüne ve pompa sistemine bağlanabilir. Alternatif olarak, bir ofis ortamında kullanılıyorsa, kanüle salin dolu bir şırınga bağlanabilir ve gerektiğinde sıvı eklenebilir. Ofis kurulumunda görüntüyü izlemek için daha küçük bir ekran mevcuttur. ${ }^{[1,18,19]}$

Turnike olmadan çalışırken, eklem içine sıvı akışı önemlidir. Arthrex (Napoli, FL) yakın zamanda eklem içine sıvı akışının artmasını sağlayan, böylece basıncı artıran ve görselleştirmeyi iyileştiren yüksek basınçlı akış kanülünü piyasaya sürmüştür. Bu özellikle diz veya omuzun arkasının görselleştirilmesine yardımcı olabilir. ${ }^{[9,12,19]}$

\section{Nano artroskopinin avantajları ve dezavantajları}

Nano artroskopinin klasik artroskopiye göre daha az cilt ve yumuşak doku hasarı, daha az kan kaybı, daha az sıvı ihtiyacı, daha az yara yeri enfeksiyon riski, daha az ağrı ve şişliğin yanı sıra erken mobilizasyon ile birlikte hızlı günlük yaşama dönüş gibi avantajları bulunmaktadır. Bunun yanında görüş açısının zorluğu, nano artroskopi ilk kurulumunun fazla maliyeti, çoğunlukla tanısal artroskopide kullanımı ve günümüzde henüz her türlü girişimsel işlemin yapılamaması dezavantajları olarak sayılabilmektedir (Tablo 2). ${ }^{[1,3,14,18,19]}$

\section{Gelecekte nano artroskopinin yeri}

Nano artroskopi kavramı 25 yıldan fazla bir süredir var olmasına rağmen, nano artroskopi hâlâ emekleme aşamasındadır ve aşılması gereken birçok engel bulunmaktadır. Ofis içi kurulumun ilk maliyeti, küçük ortopedik ofislerde engelleyici olabilmektedir ve ofis içi prosedürler için faturalandırma ve geri ödeme sorunları ortaya

Tablo 2. Nano artroskopinin avantaj ve dezavantajları ${ }^{[1,3,14,18,19]}$

\begin{tabular}{lc}
\hline Avantajları & Dezavantajları \\
\hline Minimal invaziv & Yüksek maliyet \\
Az kan kaybı & Dar görüş alanı \\
Az sıvı ihtiyacı & Kısıtlı işlem kabiliyeti \\
Enfeksiyon riskinde azalma & $0^{\circ}$ artroskopa alışma zorluğu \\
Az ağrı ve ödem & \\
Erken mobilizasyon & \\
Günübirlik işlem avantajı & \\
Hızlı işe dönüş &
\end{tabular}

çıkabilmektedir. Elbette, faturalandırma prosedürleri ve kaynakları konusunda sektör temsilcilerinden yardım alınabilmektedir. ${ }^{[19]}$

Teknoloji ilerledikçe, şüphesiz daha iyi enstrümanlar ortaya çıkacaktır. Bu durum, nano artroskopinin endikasyonlarını ve etkinliğini daha da artıracaktır. Yapılan çok sayıda maliyet analizi çalışmasının nano artroskopinin patolojik teşhis ve tedavisine yönelik daha ucuz bir yol olduğunu doğrulamasıyla, sağlık bakım maliyetlerini azaltmak için uygun bir seçenek olarak popülerlik kazanacaktır. Ortopedi ve travmatoloji uzmanları tarafından geniş çapta kabul edilecekse, bu girişimin etkinliğini doğrulayan daha fazla ve özellikle randomize kontrollü çalışmalar yapılması gerekmektedir.

Zamanın çok hızıı aktığı günümüzde, hastalıkların tanı ve tedavisinin daha hızlı ve daha doğru yapılabilmesi ve hastaların günlük daha erken hayatlarına döndürebilmesi açısından, nano artroskopi muhteşem bir yenilik olarak gözükmektedir.

Nano artroskopinin geleceği, ortopedi ve travmatoloji uzmanı olarak bizlerin götürdüğü yere doğru olacaktır. Bu teknoloji, çalışma şeklimizi ve gerçekleştirebileceğimiz prosedür türlerini değiştirme potansiyeline sahiptir. $\mathrm{Bu}$, açık cerrahiden artroskopik işlemlere geçişe benzer bir dönemin başlangıcı olacaktır. Bir öğrenme eğrisi gerektirmekle beraber hastalarımıza en iyi sonuçları vermek için yeni teknikler öğrenmek, geliştirmek ve sonuçları iyileştirmek için çaba göstermemiz gerektiğinin en belirgin örneklerindendir.

\section{KAYNAKLAR}

1. Lycans D, Lavender C. Introduction to Nanoarthroscopy. In: Lavender C, editor. Biologic and Nanoarthroscopic Approaches in Sports Medicine. Cham: Springer; 105-9. Crossref

2. Ostendorf B, Dann P, Wedekind F, Brauckmann U, Friemann $\mathrm{J}$, Koebke J, et al. Miniarthroscopy of metacarpophalangeal joints in rheumatoid arthritis. Rating of diagnostic value in synovitis staging and efficiency of synovial biopsy. J Rheumatol 1999;26(9):1901-8.

3. Ostendorf B, Peters R, Dann P, Becker A, Scherer A, Wedekind $F$, et al. Magnetic resonance imaging and miniarthroscopy of metacarpophalangeal joints: sensitive detection of morphologic changes in rheumatoid arthritis. Arthritis Rheum 2001;44(11):2492-502. Crossref

4. Gramas DA, Antounian FS, Peterfy CG, Genant HK, Lane NE. Assessment of needle arthroscopy, standard arthroscopy, physical examination, and magnetic resonance imaging in knee pain: a pilot study. J Clin Rheumatol Pract Rep Rheum Musculoskelet Dis 1995;1(1):26-34. Crossref

5. Voigt JD, Mosier M, Huber B. Diagnostic needle arthroscopy and the economics of improved diagnostic accuracy: a cost analysis. Appl Health Econ Health Policy 2014;12(5):523-35. Crossref 
6. Deirmengian CA, Dines JS, Vernace JV, Schwartz MS, Creighton RA, Gladstone JN. Use of a small bore needle arthroscope to diagnose intra-articular knee pathology: comparison with magnetic resonance imaging. Am J Orthop (Belle Mead NJ) 2018;47(2):1-5. Crossref

7. Amin N, McIntyre L, Carter T, Xerogeanes J, Voigt J. Costeffectiveness analysis of needle arthroscopy versus magnetic resonance imaging in the diagnosis and treatment of meniscal tears of the knee. Arthrosc J Arthrosc Relat Surg 2019;35(2):554-62. Crossref

8. Cooper DE. Editorial commentary: the desire to take a look: surgeons and patients must weigh the benefits and costs of in-office needle arthroscopy versus magnetic resonance imaging. Arthrosc J Arthrosc Relat Surg 2018;34(8):2436-7. Crossref

9. Gill TJ, Safran M, Mandelbaum B, Huber B, Gambardella R, Xerogeanes J. A prospective, blinded, multicenter clinical trial to compare the efficacy, accuracy, and safety of in-office diagnostic arthroscopy with magnetic resonance imaging and surgical diagnostic arthroscopy. Arthrosc J Arthrosc Relat Surg 2018;34(8):2429-35. Crossref

10. Voigt JD, Mosier M, Huber B. In-office diagnostic arthroscopy for knee and shoulder intra-articular injuries its potential impact on cost savings in the United States. BMC Health Serv Res 2014;14(203):2-9. Crossref

11. Zhang K, Crum RJ, Samuelsson K, Cadet E, Ayeni OR, de Sa D. In-office needle arthroscopy: a systematic review of indications and clinical utility. Arthrosc J Arthrosc Relat Surg 2019;35(9):2709-21. Crossref

12. McMillan S, Chhabra A, Hassebrock JD, Ford E, Amin NH. Risks and complications associated with intra-articular arthroscopy of the knee and shoulder in an office setting. Orthop J Sports Med 2019;7(9):1-7. Crossref
13. Stornebrink T, Stufkens SAS, Appelt D, Wijdicks CA, Kerkhoffs GMMJ. 2-mm diameter operative tendoscopy of the tibialis posterior, peroneal, and achilles tendons: a cadaveric study. Foot Ankle Int 2020;41(4):473-8. Crossref

14. Lavender C, Lycans D, Sina Adil SA, Kopiec A, Schmicker T. Incisionless partial medial meniscectomy. Arthrosc Tech 2020;9(3):375-8. Crossref

15. Lavender C, Lycans D, Kopiec A, Sayan A. Nanoscopic single-incision anterior labrum repair. Arthrosc Tech 2020;9(3):297301. Crossref

16. Lavender C, Lycans D, Sina Adil SA, Berdis G. Single-incision rotator cuff repair with a needle arthroscope. Arthrosc Tech 2020;9(4):419-23. Crossref

17. Dankert JF, Shimozono Y, Williamson ERC, Kennedy JG. Application of nano arthroscopy in the office setting for the removal of an intra-articular loose osseous body not identified by magnetic resonance imaging: A case report. Foot \& Ankle Surgery: Techniques, Reports \& Cases 1 2021;1(1):1-3. Crossref

18. Kamiya T, Teramoto A, Mori Y, Kitamura C, Watanabe K, Yamashita T. Nano-arthroscopic ultrasound-guided excision of unresolved Osgood-Schlatter disease. Arthrosc Tech 2021;10(6):1581-7. Crossref

19. Lavender C, Flores K. The Future of Nanoarthroscopy. In: Lavender C, editor. Biologic and Nanoarthroscopic Approaches in Sports Medicine. Cham: Springer; 2021. p. 167-9. 